\title{
Desain Pabrik Olefin berbahan baku Low Rank Coal di Kabupaten Banjar Kalimantan Selatan
}

\author{
Anastasia Ayu Pratiwi, Galih Dwi Prasetya, Kuswandi dan Gede Wibawa \\ Jurusan Teknik Kimia, Fakultas Teknologi Industri, Institut Teknologi Sepuluh Nopember (ITS) \\ Jl. Arief Rahman Hakim, Surabaya 60111 Indonesia \\ e-mail: gwibawa@chem-eng.its.ac.id
}

\begin{abstract}
Abstrak - Olefin dapat didefinisikan sebagai hidrokarbon tak jenuh yang mengandung satu atau lebih pasangan atom karbon yang memiliki ikatan rangkap. Dua jenis produk industri olefin yang paling penting adalah etilena dan propilena sebagai bahan baku utama bermacam-macam industri petrokimia. Umumnya produksi etilena dan propilena menggunakan bahan baku Naphta yang diperoleh dari pengolahan minyak bumi dan gas alam. Ketersediaan bahan baku tersebut di Indonesia terbatas dan memiliki harga jual yang fluktuatif. Dengan berorientasi pada efisiensi produksi dan mengurangi impor bahan baku, inovasi proses produksi maupun pembangunan industri olefin yang baru sangat dibutuhkan. Oleh karena itu, diperlukan bahan baku alternatif yang berlimpah dan mudah didapat serta memiliki harga yang murah, seperti batubara. Sumber daya batubara kelas rendah (low rank coal) di Indonesia mencapai 30,57 milyar ton dan perlu dioptimalkan menjadi produk yang bernilai jual lebih. Oleh karena itu, pendirian pabrik olefin dari batubara kualitas rendah sangat potensial dan penting untuk terus dikembangkan. Olefin yang terdiri dari Etilena, Propilena dan Butilena dapat diproduksi melalui indirect process dengan methanol sebagai produk intermediate. Unit - unit prosesnya terdiri dari unit preparasi batubara, unit Gasifikasi batubara untuk menghasilkan gas sintesa (syngas), unit Water Gas Shift untuk pengaturan komposisi gas $\mathrm{CO}$ dan $\mathrm{H}_{2}$, unit sintesa Methanol, unit Pemurnian Methanol dari $\mathrm{CO}_{2}$ dan $\mathrm{H}_{2} \mathrm{O}$, unit sintesa Olefin dan pemurnian produk serta unit pemisahan produk Olefin yang memisahkan campuran olefin menjadi Etilena, Propylene dan Butylene. Pabrik direncanakan beroperasi dengan kapasitas produksi sebesar 1.485 .725 ton Olefin/tahun. Berdasarkan hasil analisa ekonomi, Net Present Value (NPV) pada tahun ke sepuluh pabrik ini sebesar \$ 5.723.433.852, Internal Rate of Return (IRR) sebesar 71,68\% yang lebih besar dari bunga bank $10,5 \%$ per tahun. Modal pabrik akan kembali setelah pabrik beroperasi selama 2.51 tahun. Sedangkan brdasarkan analisa kepekaan, terdapat 3 variabel yang sangat peka terhadap fluktuasi yaitu harga katalis SAPO-34, harga produk dan kapasitas produksi Etilena, yang dapat mengakibatkan penurunan nilai IRR. Agar stabilitas IRR pabrik tetap terjaga, perlu dilakukan upaya penetapan supplier katalis untuk mendapatkan harga katalis yang stabil, mencari pasar tetap untuk penjualan produk dan menjaga stabilitas kapasitas produksi pabrik.
\end{abstract}

Kata Kunci-Indirect Process, Low Rank Coal, Olefin

\section{PENDAHULUAN}

$\mathrm{P}$ ETROKIMIA merupakan salah satu sektor industri yang memiliki peranan penting dalam mendukung kebutuhan industri lainnya, terutama industri manufaktur. Selain itu, industri petrokimia menjadi tolak ukur bagi tingkat kemajuan suatu negara dan menjadi tulang punggung bagi sebagian besar sektor industri di dunia. Dengan jumlah penduduk mencapai 250 juta jiwa dan dukungan sumber daya alam sebagai bahan baku industri petrokimia, Indonesia memiliki peluang sebagai pusat pengembangan industri petrokimia di lingkungan strategis ASEAN dan Asia. Salah satu industri petrokimia yang dimaksud adalah industri olefin etilena dan propilena.

Konsumsi Indonesia terhadap produk olefin, khususnya etilena, berdasarkan data kementrian perindustrian di tahun 2012 dan 2013, mencapai lebih dari 1,2 juta ton. Konsumsi propilena mencapai lebih dari 600 ribu ton di tahun yang sama. Sedangkan data produksi olefin dalam negeri, etilena hanya sebesar 600 ribu ton dan propilena sebesar 320 ribu ton [1]. Cadangan minyak bumi di Indonesia sebagai bahan baku nafta yang diperlukan untuk pembuatan olefin terbatas dan cenderung fluktuatif selama sepuluh tahun terakhir. Oleh karena itu, diperlukan bahan baku alternatif yang berlimpah dan mudah didapat serta memiliki harga yang murah, seperti contohnya adalah batubara. Cadangan batubara Indonesia didominasi oleh batubara dengan kualitas medium dan kualitas rendah. Sumber daya batubara kelas rendah (low rank coal) di Indonesia mencapai 30,57 milyar ton dan perlu dioptimalkan menjadi produk yang bernilai jual lebih. Oleh karena itu, pendirian pabrik olefin dari batubara kualitas rendah sangat potensial dan penting untuk terus dikembangkan. Lokasi pabrik Olefin dari Batubara Kelas Rendah (Low Rank Coal) direncanakan akan didirikan di Kabupaten Banjar, Kalimantan Selatan. Ketersediaan batu bara kelas rendah di provinsi Kalimantan Selatan memiliki potensi salah satu yang terbesar di Indonesia yaitu sebesar 536,33 Juta Ton [2]. Pabrik didirikan dekat dengan sumber bahan baku untuk tetap menjamin kontinuitas pasokan bahan baku dan menekan biaya transportasi. PT. Adaro Indonesia, Tbk., dipilih sebagai pemasok bahan baku, karena kualitas bahan baku yang sesuai dan daerah operasinya berada di provinsi Kalimantan Selatan dengan spesifikasi sebagai berikut[3].

Tabel 1. 


\begin{tabular}{cccc}
\multicolumn{4}{c}{ Spesifikasi batubara dari PT. Adaro Indonesia, Tbk } \\
\hline \hline \multirow{2}{*}{ Parameter } & Basis & Unit & Typical \\
\hline Karbon & DAF & $\%$ & 72 \\
Hidrogen & DAF & $\%$ & 5 \\
Nitrogen & DAF & $\%$ & 0,9 \\
Oksgen & DAF & $\%$ & 21,8 \\
Sulfur & DAF & $\%$ & 0,3 \\
Nilai kalor & GAR & kcal/kg & 4000 \\
HGI & - & - & 61 \\
\hline \hline
\end{tabular}

Pabrik dirancang dengan kapasitas produksi olefin total sebanyak 1.485 .725 ton/tahun, dengan rincian etilena sebanyak 957.715 ton/tahun, propilena sebanyak 445.607 ton/tahun dan butilena sebanyak 82.402 ton/tahun dengan spesifikasi.

\section{URAIAN PROSES}

Proses produksi olefin dengan bahan baku Low Rank Coal terdiri dari beberapa unit sebagai berikut.

\section{A. Unit Persiapan Bahan Baku}

Sebelum memasuki proses gasifikasi, batubara kelas rendah (low rank coal) harus dipersiapkan terlebih dahulu agar kondisinya sesuai dengan kebutuhan Gasifier yaitu dengan menggunakan hammer mill untuk mengubah ukuran batubara menjadi 1-6 mm. Kemudian low rank coal yang telah dihaluskan dimasukkan ke dalam Screener untuk memisahkan bahan baku yang tidak sesuai ukuran untuk kemudian diproses kembali dalam Hammer Mill. Sedangkan batubara yang telah sesuai ukurannya dialirkan menuju Screw Conveyor Dryer untuk dikeringkan dengan memanfaatkan arus syngas hasil gasifikasi. Batubara kemudian masuk ke Lock Hopper untuk diubah menjadi pulverized coal dari tekanan atmosfer (1 bar) menjadi 30 bar, sesuai dengan kondisi operasi di Gasifier.

\section{B. Unit Gasifikasi Batubara}

Setelah tahap persiapan, serbuk batubara diumpankan ke dalam Gasifier. Gasifier yang digunakan berjenis fluidized bed gasifier dengan tipikal proses U-Gas yang bekerja pada kondisi temperatur $900^{\circ} \mathrm{C}$ dan tekanan 30 bar[3]. Gasifier tipe ini memiliki sistem fluidisasi yang membuat heat transfer dan mass transfer antara gas dan partikel batubara solid lebih sempurna. Penggunaan temperatur yang tidak terlalu tinggi juga membuatnya lebih mudah dikontrol dan dikendalikan. Oksidan yang digunakan berupa $\mathrm{O}_{2}$ dengan tekanan 30 bar. Reaksi yang terjadi pada gasifier adalah [3]:

1. Zona Devolatilis asi

Batubara $\longleftrightarrow \mathrm{C}+\mathrm{CH}_{4}+\mathrm{CO}+\mathrm{CO}_{2}+\mathrm{H}_{2}+\mathrm{H}_{2} \mathrm{O}+\mathrm{H}_{2} \mathrm{~S}+\mathrm{COS}$ $+\mathrm{N}_{2}$

2. Zona Pembakaran
a) $\mathrm{C}+1 / 2 \mathrm{O}_{2} \longleftrightarrow \mathrm{CO}$
$\Delta \mathrm{H}=-111 \mathrm{~kJ} / \mathrm{mol}$
b) $\mathrm{CO}+1 / 2 \mathrm{O}_{2} \longleftrightarrow \mathrm{CO}_{2}$
$\Delta \mathrm{H}=-283 \mathrm{~kJ} / \mathrm{mol}$
c) $\mathrm{H} 2+1 / 2 \mathrm{O}_{2} \longleftrightarrow \mathrm{H}_{2} \mathrm{O}$
$\Delta \mathrm{H}=-242 \mathrm{~kJ} / \mathrm{mol}$

3. Zona Gasifikasi

a) Reaksi Boudourd

$\mathrm{C}+\mathrm{CO}_{2} \longleftrightarrow 2 \mathrm{CO}$

b) Reaksi Water Gas

$\mathrm{C}+\mathrm{H}_{2} \mathrm{O} \longleftrightarrow \mathrm{CO}+\mathrm{H}_{2} \quad \Delta \mathrm{H}=+131 \mathrm{~kJ} / \mathrm{mol}$

c) Reaksi Shift Convertion

$\mathrm{CO}+\mathrm{H}_{2} \mathrm{O} \longleftrightarrow \mathrm{CO}_{2}+\mathrm{H}_{2} \quad \Delta \mathrm{H}=-41 \mathrm{~kJ} / \mathrm{mol}$

d) Reaksi Metanasi

$\mathrm{C}+2 \mathrm{H}_{2} \longleftrightarrow \mathrm{CH}_{4} \quad \Delta \mathrm{H}=-75 \mathrm{~kJ} / \mathrm{mol}$

Batubara yang terbawa dalam syngas dipisahkan menggunakan Cyclone dan dikembalikan ke dalam Gasifier. Karbon (char) yang tidak bereaksi pada zona gasifikasi beserta ash turun sebagai slag di bagian bawah sedangkan syngas yang keluar akan dialirkan ke dalam Screw Conveyor Dryer. Panas ditukarkan dengan feed batubara untuk menurunkan suhu syngas dari $900^{\circ} \mathrm{C}$ menjadi $350^{\circ} \mathrm{C}$. Syngas kemudian didinginkan lebih lanjut hingga suhu $50^{\circ} \mathrm{C}$ agar terbentuk 2 fasa pada aliran sehingga air yang terkandung pada aliran dapat dipisahkan pada Water Separator Tank. Syngas, yang telah berkurang jumlah airnya, kemudian dialirkan ke dalam Desulfurizer Tank untuk menyerap kandungan $\mathrm{H}_{2} \mathrm{~S}$ yang sangat korosif dan dapat merusak katalis pada reaktor menggunakan adsorban ZnO. Syngas yang telah bersih dari pengotor $\mathrm{H}_{2} \mathrm{~S}$ kemudian dipanaskan pada Heat Exchanger menjadi $200^{\circ} \mathrm{C}$ agar sesuai dengan kondisi operasi selanjutnya.

\section{Water Gas Shift Unit}

Syngas yang dihasilkan oleh Gasification Unit kemudian dialirkan ke dalam Water Gas Shift Reactor. Tujuannya adalah untuk menambah jumlah mol $\mathrm{H}_{2}$ agar diperoleh komposisi $\mathrm{CO}$ dan $\mathrm{H}_{2}$ 1:2. Dalam reaktor ini sebagian $\mathrm{CO}$ pada syngas direaksikan dengan $\mathrm{H}_{2} \mathrm{O}$ membentuk $\mathrm{H}_{2}$. Reaksi yang terjadi merupakan reaksi eksotermis reversibel sebagai berikut:

\section{$\mathrm{CO}+\mathrm{H}_{2} \mathrm{O} \longleftrightarrow \mathrm{CO}_{2}+\mathrm{H}_{2} \quad \Delta \mathrm{H}^{\circ} 298=-41,09 \mathrm{~kJ} / \mathrm{mol}$}

Katalis yang digunakan adalah $\mathrm{CuO}-\mathrm{ZnO}-\mathrm{Al}_{2} \mathrm{O}_{3}$ dengan kondisi operasi pada suhu $200^{\circ} \mathrm{C}$ dan tekanan 29 bar [5]. Produk Syngas dari unit ini kemudian dikondisikan menjadi bertekanan 51 suhu $200^{\circ} \mathrm{C}$ agar sesuai dengan kondisi operasi reaktor selanjutnya.

\section{Unit Sintesa Metanol}

Unit ini mereaksikan Syngas menjadi intermediate produk berupa metanol. Katalis yang digunakan berbasis tembaga dengan campuran $\mathrm{ZnO}$. Senyawa $\mathrm{H}_{2} \mathrm{~S}$ yang masih terdapat dalam Syngas dapat menurunkan fungsi katalis tembaga pada reaktor sintesis metanol. Di dalam reaktor ini CO dapat bereaksi dengan hidrogen membentuk metanol sesuai dengan reaksi:

$$
\mathrm{CO}+2 \mathrm{H}_{2} \longleftrightarrow \mathrm{CH}_{3} \mathrm{OH}
$$

Reaksi ini bersifat reversibel dan eksotermis dengan kondisi operasi pada suhu $200^{\circ} \mathrm{C}$ dan tekanan 51 bar [6]. Untuk menjaga suhu operasi reaktor, reaktor ini dilengkapi dengan jaket pedingin. Produk berupa methanol dialirkan ke dalam Heat Exchanger untuk didinginkan hingga suhu $178,33^{\circ} \mathrm{C}$ lalu 
dialirkan ke Methanol Cooler untuk menurunkan suhu hingga $33^{\circ} \mathrm{C}$. Pada suhu tersebut, akan terbentuk 2 fasa yang kemudian dipisahkan pada Methanol Separator untuk memisahkan gasgas ringan yang tidak digunakan lagi pada proses selanjutnya dengan produk metanol. Liquid dialirkan menuju Heat Exchanger untuk pertukaran panas dengan aliran sebelumnya hingga menjadi $180^{\circ} \mathrm{C}$.

\section{E. Unit Pemurnian Metanol}

Aliran yang mengandung produk metanol kemudian dipurifikasi dari komponen pengotor yang tidak dibutuhkan lagi. Pertama-tama digunakan Distillation Column untuk memisahkan larutan metanol dengan gas $\mathrm{CO}_{2}$ dan gas-gas ringan lain yang masih terkandung dalam aliran.

Metanol dari bawah kolom dialirkan ke Valve untuk menurunkan tekanan menjadi 3 bar. Kemudian dialirkan ke kolom distilasi dengan suhu antara titik didih methanol $\left(65^{\circ} \mathrm{C}\right)$ dan titik didih air $\left(100^{\circ} \mathrm{C}\right)$ untuk memisahkan gas metanol dari bottom liquid berupa air. Gas yang mengandung 90\%-mol metanol kemudian dialirkan ke unit sintesa Olefin.

\section{F. Unit Sintesa Olefin}

Gas metanol dialirkan ke Olefin Heat Exchanger untuk mengondisikan suhunya menjadi $489,9^{\circ} \mathrm{C}(763 \mathrm{~K})$ agar sesuai dengan kondisi operasi reaktor. Kemudian aliran diarahkan menuju Ethylene Synthesis Reactor. Katalis yang digunakan adalah SAPO-34 yang terdiri dari $\mathrm{Al}_{2} \mathrm{O}_{3}: \mathrm{P}_{2} \mathrm{O}_{5}: 0.6 \mathrm{SiO}_{2}: 0.5$ TEAOH : 1.5 morpholine. Reaksi yang terjadi pada reaktor ini adalah [6]:

$$
\begin{aligned}
& 2 \mathrm{CH}_{3} \mathrm{OH} \longrightarrow \mathrm{C}_{2} \mathrm{H}_{4}+2 \mathrm{H}_{2} \mathrm{O} \\
& 3 \mathrm{CH}_{3} \mathrm{OH} \longleftrightarrow \mathrm{C}_{3} \mathrm{H}_{6}+3 \mathrm{H}_{2} \mathrm{O} \\
& 4 \mathrm{CH}_{3} \mathrm{OH} \longleftrightarrow \mathrm{C}_{4} \mathrm{H}_{8}+4 \mathrm{H}_{2} \mathrm{O}
\end{aligned}
$$

Gas hasil reaksi berupa campuran gas etilena, propilena, butilena, air dan komponen-komponen pengotor lainnya. Aliran produk kemudian didinginkan hingga suhu $216,14^{\circ} \mathrm{C}$ agar terbentuk 2 fasa yang kemudian dipisahkan kandungan airnya dalam separator. Selanjutnya gas dialirkan ke Fixed Bed Water Removal yang menggunakan adsorban berupa Molecular Sieve untuk menyerap sisa air yang belum terpisah dari gas. Setelah itu, gas dikompresi hingga tekanan 5 bar untuk mempermudah proses pemurnian dan dialirkan ke GasGas Heat Exchanger untuk dipertukarkan panasnya.

\section{G. Unit Pemisahan Olefin}

Produk olefin yang merupakan campuran etilena, propilena, dan 1-butena dipisahkan untuk mendapatkan masing-masing komponennya. Pertama-tama produk gas dimasukkan ke dalam Depropanizer untuk memisahkan bottom product berupa komponen olefin yang lebih berat dengan overhead gas berupa campuran olefin ringan (etilena dan propilena). 1butena yang dihasilkan pada bottom product kemudian ditampung pada Butylene Storage.

Overhead gas dialirkan ke dalam Deethanizer untuk memisahkan etilena dengan propilena. Produk atas etilena dalam fasa liquid ditampung dalam Ethylene Storage dan produk bawah propilena ditampung dalam Propylene Storage.

\section{MATERIAL BALANCE}

Hasil perhitungan material balance menunjukkan bahwa kapasitas produksi olefin sebesar 1.485 .725 ton/tahun yang terbagi menjadi $957.715,42$ ton etilena/tahun, 445.607,32 ton propilena/tahun, dan $82.402,22$ ton butylene/tahun membutuhkan bahan baku sebesar 10 juta ton Low Rank Coal / tahun [7]-[11]. Perbandingan spesifikasi minimum industri dan

\begin{tabular}{|c|c|c|c|c|c|}
\hline \multicolumn{3}{|c|}{ Etilena } & \multicolumn{3}{|c|}{ Propilena } \\
\hline Komposisi & Syarat & Hasil & Komposisi & Syarat & Hasil \\
\hline Etilena & $99 \mathrm{~mol} \%$ & $\begin{array}{l}99.6 \\
\text { mol\% }\end{array}$ & Propilena & $\begin{array}{c}99.6 \\
\mathrm{~mol} \%\end{array}$ & $\begin{array}{l}99.94 \\
\text { mol\% }\end{array}$ \\
\hline Hidrogen & $\begin{array}{c}\leq 10 \mathrm{~mol} \\
\mathrm{ppm}\end{array}$ & $\begin{array}{l}0 \mathrm{~mol} \\
\mathrm{ppm}\end{array}$ & Hidrogen & $\begin{array}{l}10 \mathrm{~mol} \\
\mathrm{ppm}\end{array}$ & $\begin{array}{c}0 \mathrm{~mol} \\
\mathrm{ppm}\end{array}$ \\
\hline Oksigen & $\begin{array}{c}\leq 1 \mathrm{~mol} \\
\mathrm{ppm}\end{array}$ & $\begin{array}{l}0 \mathrm{~mol} \\
\mathrm{ppm}\end{array}$ & Oksigen & $\begin{array}{c}2 \mathrm{~mol} \\
\mathrm{ppm}\end{array}$ & $\begin{array}{l}0 \mathrm{~mol} \\
\mathrm{ppm}\end{array}$ \\
\hline $\begin{array}{c}\text { Karbon } \\
\text { monoksida }\end{array}$ & $\begin{array}{c}\leq 2 \mathrm{~mol} \\
\mathrm{ppm}\end{array}$ & $\begin{array}{l}0 \mathrm{~mol} \\
\mathrm{ppm}\end{array}$ & $\begin{array}{c}\text { Karbon } \\
\text { monoksida }\end{array}$ & $\begin{array}{l}5 \mathrm{~mol} \\
\mathrm{ppm}\end{array}$ & $\begin{array}{c}0 \text { mol } \\
\text { ppm }\end{array}$ \\
\hline Air & $\begin{array}{c}\leq 10 \mathrm{~mol} \\
\mathrm{ppm}\end{array}$ & $\begin{array}{l}0 \mathrm{~mol} \\
\mathrm{ppm}\end{array}$ & $\begin{array}{l}\text { Karbon } \\
\text { dioksida }\end{array}$ & $\begin{array}{l}5 \mathrm{~mol} \\
\mathrm{ppm}\end{array}$ & $\begin{array}{c}0.036 \mathrm{~mol} \\
\mathrm{ppm}\end{array}$ \\
\hline Methanol & $\begin{array}{c}\leq 5 \mathrm{~mol} \\
\mathrm{ppm}\end{array}$ & $\begin{array}{c}0 \mathrm{~mol} \\
\mathrm{ppm}\end{array}$ & Air & $\begin{array}{l}10 \mathrm{~mol} \\
\mathrm{ppm}\end{array}$ & $\begin{array}{l}0 \mathrm{~mol} \\
\mathrm{ppm}\end{array}$ \\
\hline $\begin{array}{l}\text { Total } \\
\text { Sulfur }\end{array}$ & $\begin{array}{l}\leq \underset{\mathrm{ppm}}{1 \text { mass }} \\
\text { P }\end{array}$ & $\begin{array}{c}0.00029 \\
\text { mass ppm }\end{array}$ & Methanol & $\begin{array}{l}5 \mathrm{~mol} \\
\mathrm{ppm}\end{array}$ & $\begin{array}{c}0 \mathrm{~mol} \\
\mathrm{ppm}\end{array}$ \\
\hline & & & $\begin{array}{l}\text { Total } \\
\text { Sulfur }\end{array}$ & $\begin{array}{c}2 \text { mass } \\
\text { ppm }\end{array}$ & $\begin{array}{c}0.0036 \\
\text { mass ppm }\end{array}$ \\
\hline
\end{tabular}
spesifikasi produk yang dihas ilkan adalah sebagai berikut [12].

Tabel 2. Perbandingan syarat komposisi produk dengan hasil

\section{ANALISA EKONOMI}

Dalam melakukan analisa ekonomi, digunakan asumsi modal kerja sebesar 6 bulan biaya pengeluaran yang terdiri dari biaya bahan baku ditambah dengan biaya operasi, eskalasi harga bahan baku sebesar nilai inflasi $6 \%$ setiap tahun, eskalasi biaya operasi yang meliputi biaya bahan penolong, biaya utilitas dan biaya tetap sebesar nilai inflasi $6 \%$ setiap tahun, sumber dana investasi berasal dari modal sendiri sebesar $20 \%$ biaya investasi dan pinjaman jangka pendek sebesar $80 \%$ biaya investasi dengan bunga sebesar $10.5 \%$ per tahun yang akan dibayar dalam jangka waktu 48 bulan (4 tahun), penyusutan investasi alat $\&$ bangunan terjadi dalam waktu 10 tahun secara straight line. Hasil analisa keuangan menunjukkan bahwa dibutuhkan Total Investment Cost 1.049,5 MUSD dengan bunga 10,5\% per tahun. Dalam 10 tahun, Nilai NPV sebesar 5.723,4 MUSD, IRR sebesar 71,68\% yang lebih tinggi dari suku bunga bank per tahun sebesar 10,5\% dengan pengembalian modal selama 2,51 tahun. Berdasarkan analisa kepekaan terhadap 4 paramater sensitifitas yaitu fluktuasi biaya investasi, harga bahan baku, harga jual dari produk dan kapasitas produksi, terdapat 3 variabel yang sangat peka terhadap fluktuasi yaitu harga katalis SAPO-34, harga produk etilena, dan kapasitas produksi etilena. Variabel-variabel tersebut dapat menyebabkan ketidakstabilan dari IRR. Oleh karena itu diperlukan upaya-upaya penyelesaian dalam menjaga stabilitas IRR pabrik agar tidak terjadi kerugian, antara lain yaitu penetapan supplier katalis untuk mendapatkan harga 
katalis yang stabil, mencari pasar tetap untuk penjualan produk dan menjaga stabilitas kapasitas produksi pabrik [13].

\section{KESIMPULAN/RINGKASAN}

Pabrik Olefin dari Low Rank Coal layak untuk didirikan ditinjau dari hasil analisa ekonomi didapatkan nilai NPV 10 tahun sebesar 5.723,4 MUSD, IRR sebesar 71,68\% yang lebih tinggi dari suku bunga bank per tahun sebesar 10,5\% dengan pengembalian modal selama 2,51 tahun, dan berdasarkan analisa parameter sensitivitas, diperlukan upaya menjaga stabilitas IRR pabrik melalui penetapan supplier katalis untuk mendapatkan harga katalis yang stabil, mencari pasar tetap untuk penjualan produk dan menjaga stabilitas kapasitas produksi pabrik.

\section{UCAPAN TERIMA KASIH}

Penulis mengucapkan terima kasih kepada keluarga Laboratorium Thermodinamika Jurusan Teknik Kimia FTI ITS yang telah memberikan dukungan dan saran terhadap penulis an artikel ini.

\section{DAFTAR PUSTAKA}

[1] Indonesia. Kementerian Energi dan Sumber Daya Mineral. Pusat Data dan Informasi. Handbook of Energy \& Economic Statistics of Indonesia. Jakarta: Pusat Data dan Informasi Kementrian ESDM (2014).

[2] Soemanto, Ariana. Indonesia Pathway 2050 Calculator: Penyediaan Minyak dan Gas Bumi. 2014. Jurnal Mineral \& Energi. Litbang Energi dan Sumber Daya Mineral, Kementerian Energi dan Sumber Daya Mineral. (2014)

[3] Adimnistrator. (2014, September). Adaro Envirocoal Coal Specifications. Available: http://www.adaro-envirocoal.com

[4] Higman, Christopher and Van Der Burgt, Marteen. Gasification $2^{\text {nd }}$ Ed. Boston : Gulf Profesional Publishing. (2008).

[5] Smith R. J., Byron. Loganathan, Muruganandam. Shantha, Murthy Shekhar. A review of the Water Gas Shift Reaction Kinetics. International Journal of Chemical Reactor Engineering. 2010. Volume 8: Review R4.

[6] Xiang, Dong. Yang, Siyu. Liu, Xia. Mai, Zihao. Qian, Yu. Technoeconomic performance of the coal-olefins process with CCS. Chemical Engineering Journal. 2014. 240(2014): 45-54.

[7] Himmelblau, David M. Riggs, James B. "Basic Principles and Calculations in Chemical Engineering", $7^{\text {th }}$ Edition. New Jersey: Prentice Hall International Series in the Physical and Chemical Engineering Sciences (2004).

[8] Van Ness, Smith. Introduction to Chemical Engineering Thermodynamics, $4^{\text {th }}$ ed. Singapore: Mc Graw-Hill Inc. (1967)

[9] Ulrich, Gael D. A guide to Chemical Engineering Process Design and Economic. Canada: John Wiley and Sons. (1984).

[10] Perry, R. H. Green, Don W. Perry's Chemical Engineers' Handbook, 6th Ed. New York : Mc Graw-Hill. (1984)

[11] Kern, Donald Q. Process Heat Transfer. Tokyo : Mc Graw-Hill Book Company. (1965).

[12] Kriel, Ludwig. Winter, Olaf. Stork, Karl. Ethylene, keystone to the Petrochemical Industry. New York : M. Dekker. (1980).

[13] Klaus. D.Timmerhaus and Ronald. E.W, "Plant Design and Economics for Chemical Engineering", 5t International Edition McGraw Hill Book Company (2003). 